\title{
Analisis Kebutuhan Pengetahuan Keselamatan dan Kesehatan Kerja (K3) Terhadap Siswa Praktik Kerja Industri di SMK Negeri 1 Kaidipang
}

\author{
Sri Astuti Binol 1), Hasmah 2), Frice L. Desei ${ }^{3)}$ \\ 1),2),3) Jurusan Teknik Sipil, Fakultas Teknik, Universitas Negeri Gorontalo \\ email: sriastutirahardjo@gmail.com
}

\begin{abstract}
Abstrak
Pemahaman tentang Kesehatan dan Keselamatan Kerja dalam Prakerin masih sangat rendah. Untuk itu perlu dilakukan penelitian dengan tujuan untuk menganalisis Kebutuhan Pengetahuan Dan Penerapan Keselamatan dan Kesehatan Kerja siswa SMK Negeri 1 Kaidipang saat melakukan Praktik Kerja Industri. Metode penelitian menggunakan penelitian kuantitatif dengan metode angket dan observasi dengan 2 macam variabel, yaitu 1) Kebutuhan Pengetahuan Keselamatan dan Kesehatan Kerja (X), dan 2) Penerapan Pengetahuan K3 saat Praktik Kerja Industri $(Y)$. Pengujian dengan taraf signifikansi $(\alpha)$ sebesar $5 \%$, menunjukan : (1) besarnya pengaruh Kebutuhan Pengetahuan Keselamatan dan Kesehatan Kerja terhadap Penerapan Keselamatan dan Kesehatan Kerja saat Praktik Kerja Industri, hal ini dibuktikan dengan nilai $R$ Square sebesar 0,358 atau $35,8 \%$ yang artinya bahwa variable Kebutuhan Pengetahuan Keselamatan dan Kesehatan Kerja hanya memberikan kontribusi sebesar 35,8\% terhadap Penerapan K3 (2) pengaruh positif dalam Kebutuhan Pengetahuan K3 terhadap Penerapan Keselamatan dan Kesehatan Kerja saat Praktik Kerja Industri jurusan kelas XI dan kelas XI dijurusan Teknik Gambar Bangunan dengan bukti nilai, thitung > ttabel $(4,604>$ 2,02439). Kebutuhan Pengetahuan Keselamatan dan Kesehatan Kerja dapat mempengaruhi kesadaran siswa dalam Penerapan Keselamatan dan Kesehatan Kerja karena siswa dapat mengetahui akibat dari tidak memperhatikan Keselamatan dan Kesehatan Kerja.
\end{abstract}

Kata kunci: Keselamatan dan Kesehatan Kerja, Praktik Kerja Industri

\begin{abstract}
This research aims to analyze the knowledge necessity and implementation of the occupational health and safety (OHS) of students in SMK Negeri 1 Kaidipang while taking the industrial work practice. This is a quantitative research by applying questionnaires and observation with 2 variables, those are; 1) the knowledge necessity of the occupational health and safety $(X)$ and 2) the implementation of the occupational health and safety in the industrial work practice $(Y)$.. The test with the significance level (a) of 5\%. It shows that: (1) Knowledge necessity of occupational health and safety greatly influences its implementation during the industrial work practices, this is evidenced by the $R$ Square value of 0.358 or $35.8 \%$ which means that the knowledge necessity of the occupational health and safety variable only contributes $35.8 \%$ to its implementation during the industrial work practices. (2) the knowledge necesssity of the OHS positively influences its implementation during the industrial work practice of students in class XI and XII majoring in Architecture with proof of value, count> cable $(4,604>2.02439)$. The knowledge necessity of occupational health and safety can affect students' awareness in its implementation because students can know the consequences of not paying attention to occupational health and safety
\end{abstract}

Keywords: Occupational Health and Safety, Industrial Work Practice 


\section{Pendahuluan}

Sekolah Menengah Kejuruan (SMK) menurut Undang-Undang Negara Republik Indonesia Nomor 20 Tahun 2003 tentang Sistem Pendidikan Nasional Pasal 18 dijelaskan bahwa Pendidikan Kejuruan merupakan pendidikan menengah yang mempersiapkan peserta didik untuk bekerja pada bidang tertentu. SMK sebagai salah satu institusi yang menyiapkan tenaga kerja, dituntut mampu menghasilkan tenaga kerja yang terampil sebagaimana diharapkan dunia kerja. Salah satu tujuan pendidikan SMK menurut Peraturan Menteri Pendidikan Nasional (Permendiknas) Nomor 22 Tahun 2006, Pendidikan Kejuruan bertujuan untuk meningkatkan kecerdasan, pengetahuan, kepribadian, akhlak mulia, serta keterampilan peserta didik untuk hidup mandiri dan mengikuti pendidikan lebih lanjut sesuai dengan program kejuruannya.

Keterlibatan secara langsung dalam dunia kerja dengan tingkat resiko bahaya yang tinggi, mengharuskan siswa memiliki pengetahuan tentang Keselamatan dan Kesehatan Kerja. Hal ini bertujuan agar siswa dan semua pihak yang terlibat terhindar dari bahaya akibat kecelakaan kerja. Berdasarkan hal tersebut, ada baiknya sebelum siswa mengikuti Praktik Kerja Industri siswa memiliki pengetahuan Kesehatan dan Keselamatan Kerja. Akan tetapi, siswa di SMK Negeri 1 Kaidipang khususnya program keahlian Teknik Gambar Bangunan, tidak mendapat mata pelajaran yang khusus membahas Keselamatan dan Kesehatan Kerja. Dimana seharusnya pengetahuan Keselamatan dan Kesehatan Kerja tersebut perlu diberikan kepada siswa kelas $\mathrm{X}$ sebagai bekal saat dikelas XI dan kelas XII sebelum mereka mengikuti Praktik Kerja Industri. Dengan tidak adanya mata pelajaran yang membahas masalah Kesehatan dan Keselamatan kerja, maka akan mempengaruhi perilaku siswa saat melaksanakan Praktik Kerja Industri.

Tujuan dari penelitian ini adalah sebagai berikut.

1) Menganalisis kebutuhan pengetahuan siswa kelas $X I$ program keahlian Teknik Gambar Bangunan SMK Negeri 1 Kaidipang tentang pengetahuan Keselamatan dan Kesehatan Kerja.

2) Menganalisis Penerapan Pengetahuan Keselamatan dan Kesehatan Kerja siswa SMK Negeri 1 Kaidipang saat melaksanakan Praktik Kerja Industri.

Adapun manfaat dari penelitian ini adalah sebagai berikut.

1) Manfaat Teoritis

Hasil penelitian ini diharapkan dapat memberikan sumbangan informasi bagi penelitian dimasa yang akan datang, terutama yang berhubungan dengan Keselamatan dan Kesehatan Kerja bagi siswa SMK. 
2) Manfaat Praktis

a. Manfaat untuk Siswa

Diharapkan siswa SMK Negeri 1 Kaidipang khususnya jurusan Teknik Gambar Bangunan dapat memacu diri agar lebih memingkatkan pengetahuan Kesehatan dan Keselamatan Kerja (Keselamatan dan Kesehatan Kerja) guna mempersiapkan diri untuk memasuki dunia kerja.

b. Manfaat untuk Guru

1) Diharapkan dapat dijadikan bahan masukan agar lebih meningkatkan pengetahuan siswa terhadap Kesehatan dan Keselamatan Kerja (K3).

2) Diharapkan untuk lebih meningkatkan pembekalan pengetahuan Kesehatan dan Keselamatan Kerja (K3) pada siswa yang akan Praktik Kerja Industri.

c. Manfaat untuk Peneliti

Untuk peneliti dapat menambah pengetahuan, wawasan, serta pengalaman mengenai Kesehatan dan Keselamatan Kerja.

\section{Metode}

Penelitian ini menggunakan penelitian kuantitatif dengan metode angket dan observasi. Angket atau kuisioner merupakan sejumlah pertanyaan atau pernyataan tertulis tentang data faktual atau opini yang berkaitan dengan diri responden, yang dianggap fakta atau kebenaran yang diketahui dan perlu dijawab oleh responden (Anwar, Suroyo ; 2009 : 168). Menurut Sugiyono (2016 : 233) observasi adalah suatu metode atau cara untuk menganalisis dan melakukan pencatatan yang dilakukan secara sistematis, tidak hanya terbatas dari orang, tetapi juga obyekobyek alam yang lain.

1. Regresi Linear Sederhana (Uji t)

Regresi linear sederhana didasarkan pada hubungan fungsional maupun kasual satu variabel independen dengan satu variabel dependen (Sugiyono 2012 : 270). Analisis regresi linear sederhana digunakan untuk mengetahui pengaruh variabel $\mathrm{X}$ terhadap variabel $\mathrm{Y}$. Pengujian hipotesis dilakukan dengan mencari nilai thitung.

\section{Koefisien Determinasi}

Koefisien determinasi digunakan untuk menyatakan besar kecilnya pengaruh variabel bebas terhadap veriabel terikat. Nilai R2 mempunyai interval $0-1$ $(0 \leqslant R 2 \leqslant 1)$. 
Tahapan Penelitian

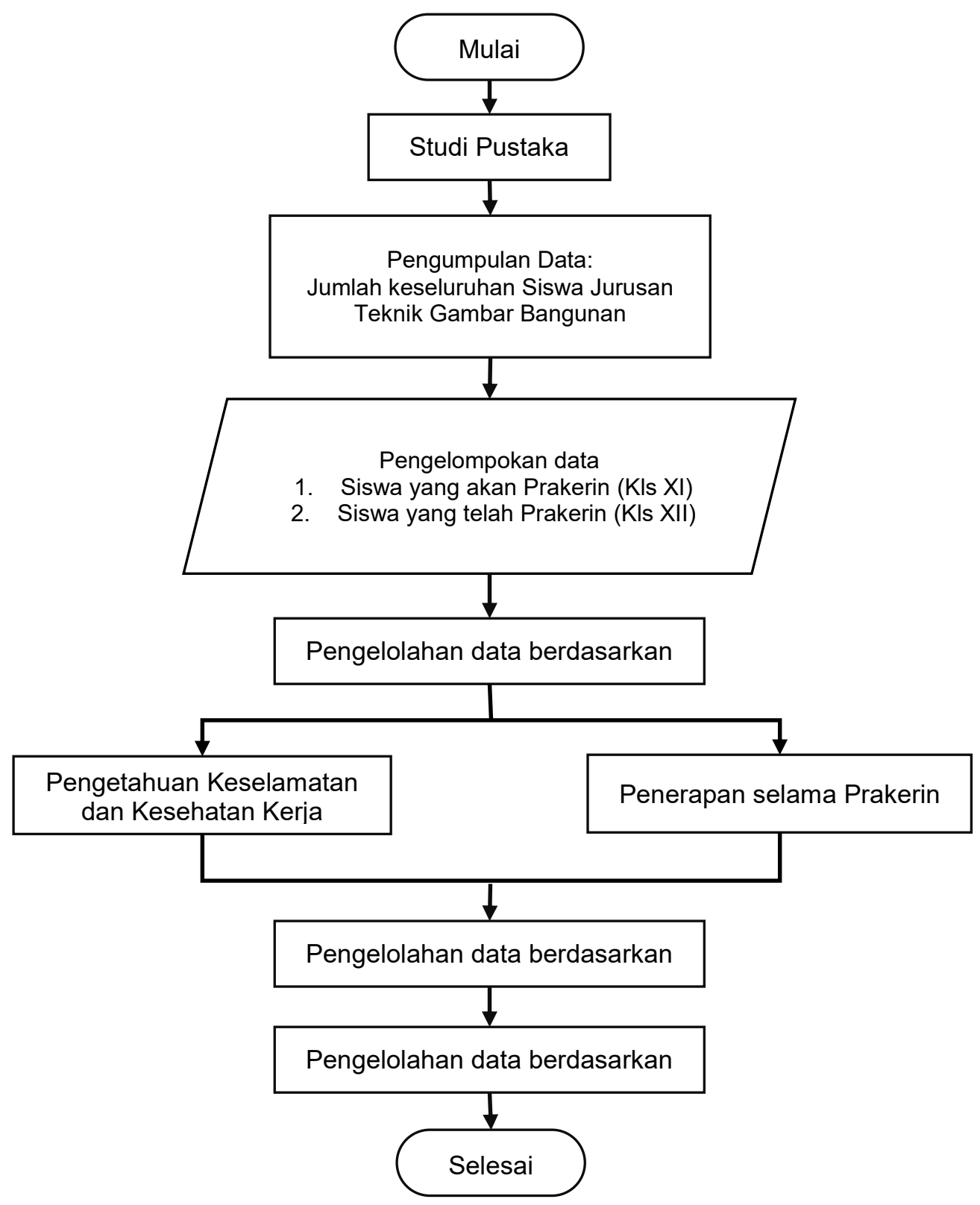

Gambar 1. Bagan Alir Penelitian 


\section{Hasil dan Pembahasan}

\section{Hasil}

\section{Hasil Uji Validitas}

Tabel 1. Hasil Uji Validitas

\begin{tabular}{clccc}
\hline No & \multicolumn{1}{c}{ Variabel } & $\begin{array}{c}\text { Jumlah } \\
\text { Item }\end{array}$ & $\begin{array}{c}\text { Jumlah Item } \\
\text { yang Gugur }\end{array}$ & $\begin{array}{c}\text { No. Item } \\
\text { yang Gugur }\end{array}$ \\
\hline 1. & $\begin{array}{l}\text { Pengetahuan } \\
\text { Keselamatan dan } \\
\text { Kesehatan Kerja } \\
\begin{array}{l}\text { Penerapan Pengetahuan } \\
\text { Keselamatan dan } \\
\text { Kesehatan Kerja saat } \\
\text { praktik kerja industry }\end{array}\end{array}$ & 28 & 8 & $\begin{array}{c}1,13,14,15, \\
19,22,23, \\
26\end{array}$ \\
$\quad$ Jumlah total item yang gugur & 28 & 3 & $9,11,15$ \\
\hline
\end{tabular}

\section{Hasil Analisis Deskriptif}

Tabel 2. Hasil Analisis Deskriptif

\begin{tabular}{ccc}
\hline & $\begin{array}{c}\text { Kebutuhan Pengetahuan } \\
\text { Keselamatan dan Kesehatan } \\
\text { Kerja }\end{array}$ & $\begin{array}{c}\text { Penerapan Keselamatan } \\
\text { dan Kesehatan Kerja }\end{array}$ \\
\hline $\mathrm{N}$ & 40 & 40 \\
Mean & 85,139 & 91,417 \\
Median & 87,5 & 92 \\
Modus & 88 & 92 \\
ST. Dev & 9,156 & 8,016 \\
Range & 36 & 37 \\
Min & 63 & 73 \\
Max & 99 & 110 \\
Sum & 3065 & 3291 \\
\hline
\end{tabular}

\section{Pembahasan}

Berdasarkan hasil pengolahan data menunjukan bahwa Kebutuhan Pengetahuan Keselamatan dan Kesehatan Kerja dengan populasi sebanyak 40 siswa gabungan antara kelas XI dan kelas XII jurusan Teknik Gambar Bangunan, Pengetahuan Keselamatan dan Kesehatan Kerja sebesar 4,604 pada 0,05. Besarnya $t_{\text {tabel }}(\alpha=0,05)$ dengan $\mathrm{df}$ (degree of freedom) 38 (dari rumus $\mathrm{df}=\mathrm{n}-\mathrm{k}=40-2=38$ ) dan $\alpha$ 0,05 sebesar 2,02439. Variabel pengetahuan $>\alpha(4,604>0,05), t_{\text {hitung }}>t_{\text {tabel }}$ $(4,604>2,02439)$, serta taraf signifikan dari $\alpha$ dari variabel $X<$ taraf signifikan $5 \%(0,000$ $<0,05$ ). Berdasarkan perhitungan analisis regresi sederhana (uji t) Kebutuhan Pengetahuan Keselamatan dan Kesehatan Kerja (X) terhadap Penerapan Pengetahuan Keselamatan dan Kesehatan Kerja saat Praktik Kerja Industri (Y), besarnya pengaruh Kebutuhan Pengetahuan Keselamatan dan Kesehatan Kerja terhadap Penerapan Pengetahuan Keselamatan dan Kesehatan Kerja saat Praktik 
Kerja Industri adalah sebesar 0,358 (35,8\%) yang artinya bahwa variabel Kebutuhan Pengetahuan Keselamatan dan Kesehatan Kerja memberikan kontribusi hanya sebesar 35,8\% terhadap Penerapan Pengetahuan Keselamatan dan Kesehatan Kerja saat Praktik Kerja Industri yang tersebar pada pengertian dan tujuan Keselamatan dan Kesehatan Kerja, sikap dan perhatian terhadap Keselamatan dan Kesehatan Kerja, alat dan bahan serta identifikasi penyebab kecelakaan, penggunaan APD, kenyamanan ruang praktik serta pedoman dan instruktur.

\section{Kesimpulan}

Berdasarkan data yang diperoleh dari hasil analisis, maka kesimpulan yang dapat diambil dalam penelitian ini yaitu.

1. Besarnya pengaruh Kebutuhan Pengetahuan Keselamatan dan Kesehatan Kerja terhadap Penerapan Keselamatan dan Kesehatan Kerja saat Praktik Kerja Industri, hal ini dibuktikan dengan nilai $\mathrm{R}$ Square sebesar 0,358 atau 35,8\% yang artinya bahwa variabel Kebutuhan Pengetahuan Keselamatan dan Kesehatan Kerja hanya memberikan kontribusi sebesar 35,8\% terhadap Penerapan Keselamatan dan Kesehatan Kerja saat Praktik Kerja Industri, yang tersebar pada pengertian dan tujuan Keselamatan dan Kesehatan Kerja, sikap dan perhatian terhadap Keselamatan dan Kesehatan Kerja, alat dan bahan serta identifikasi penyebab kecelakaan, penggunaan APD, kenyamanan ruang praktik serta pedoman dan instruktur.

2. Pengaruh positif dalam Kebutuhan Pengetahuan Keselamatan dan Kesehatan Kerja terhadap Penerapan Keselamatan dan Kesehatan Kerja saat Praktik Kerja Industri jurusan kelas XI dan kelas XI dijurusan Teknik Gambar Bangunan dengan bukti nilai , $t_{\text {hitung }}>t_{\text {tabel }}(4,604>2,02439)$. Kebutuhan Pengetahuan Keselamatan dan Kesehatan Kerja dapat mempengaruhi kesadaran siswa dalam Penerapan Keselamatan dan Kesehatan Kerja karena siswa dapat mengetahui akibat dari tidak memperhatikan Keselamatan dan Kesehatan Kerja.

\section{Daftar Pustaka}

A.A. Anwar Prabu Mangkunegara. (2013). Manajemen Sumber Daya Manusia Perusahaan. Bandung: PT. Remaja Rosda Karya.

Kementrian Sekretarian Negara Republik Indonesia. 2006. Peraturan Menteri Pendidikan Nasional (PERMENDIKNAS) Nomor 22 Tahun 2006 Tentang Pendidikan Kejuruan. Jakarta : Kementrian Sekertariat Negara Republik Indonesia. 
Sugiyono. (2012). Metode Penelitian Pendidikan Pendekatan Kuantitatif, Kualitatif, dan R\&D. Bandung : Alfabeta.

Sugiyono. (2016). Metode Penelitian Kuantitatif, Kualitatif dan R\&D. Bandung: Alfabet. 